\title{
AVALIAÇÃO DA SUSTENTABILIDADE EM EDIFÍCIOS MULTIFAMILIARES DO PROGRAMA MINHA CASA MINHA VIDA EM CRICIÚMA, SC, SEGUNDO O SELO CASA AZUL
}

\author{
Daniel Comin da Silva (UFSC); Orientadora: \\ Lisiane Ilha Librelotto, Dra. (UFSC); Coorientador: \\ Anderson Claro, Dr. (UFSC).
}

\section{INTRODUÇÃO}

O Programa Minha Casa Minha Vida (PMCMV) foi lançado pelo Governo Federal em 2009, concedendo subsídios e empréstimos facilitados por meio da Caixa Econômica Federal, com o intuito de ampliar o acesso à moradia, além de reduzir o déficit habitacional brasileiro que, segundo a Fundação João Pinheiro (2014), é de 5,79 milhões de moradias. No ano seguinte, a Caixa Econômica Federal lançou o Selo Casa Azul (SCA), com o objetivo de intensificar e incentivar a adoção de ações sustentáveis nos edifícios residenciais brasileiros (CAIXA, 2010).

Embora ambos os programas estejam vinculados à CAIXA, eles não estão relacionados, não sendo necessária a certificação residencial para empreendimentos financiados e subsidiados pelo PMCMV. Esta poderia ser uma grande contribuição do poder público para viabilizar, intensificar e incentivar a sustentabilidade dos edifícios residenciais brasileiros (CAIXA, 2010).

O PMCMV completou cinco anos em abril de 2014, contratando 3,39 milhões de unidades, beneficiando mais de seis milhões de pessoas, com um investimento de RS 234 bilhões (CAIXA, 2014). Por outro lado, foram certificados pelo SCA, até o mês de julho de 2015, somente 10 empreendimentos, totalizando 1.499 unidades habitacionais (CAIXA, 2015).

Em Criciúma, SC, a população urbana atingiu $98,61 \%$ em 2010. Associado a isto, o déficit habitacional também é crescente, intensificando as demandas habitacionais. O município tem a construção civil como uma das suas principais atividades econômicas e, o PMCMV, como o seu principal programa habitacional (SSSH, 2012). No entanto, nenhum dos 27 conjuntos habitacionais do programa, aprovados para construção na cidade, sequer se candidataram ao SCA. Estes edifícios possuem pouca diversidade de configurações, além de, normalmente, estarem situados nas periferias da cidade. Estes fatores não contribuem para a sua sustentabilidade, à medida que tratam a singularidade das necessidades dos usuários com projetos padronizados e de produção em escala. Por outro lado, também aumentam os deslocamentos urbanos, além de impulsionarem a ocupação de áreas, normalmente, pouco providas de infraestrutura urbana (SRC, 2015).

Este resumo apresenta alguns resultados obtidos em dissertação de mestrado do Programa de Pós-Graduação em Arquitetura e Urbanismo da Universidade Federal de Santa Catarina, cujo objetivo geral é avaliar a sustentabilidade socioambiental de edifícios multifamiliares do PMCMV, utilizando como ferramenta o SCA.

\section{PROCEDIMENTOS METODOLÓGICOS}

A pesquisa realizada dividiu-se em cinco etapas: revisão bibliográfica; seleção dos estudos de caso; análise dos estudos de caso; proposição; análise dos resultados.

Para coletar as informações necessárias para o presente estudo, foi realizado contato com o Departamento de Planejamento Físico Territorial e Departamento de Habitação do Município de Criciúma, além de contato com a 
Figura 1:Custo adicional por metro quadrado.

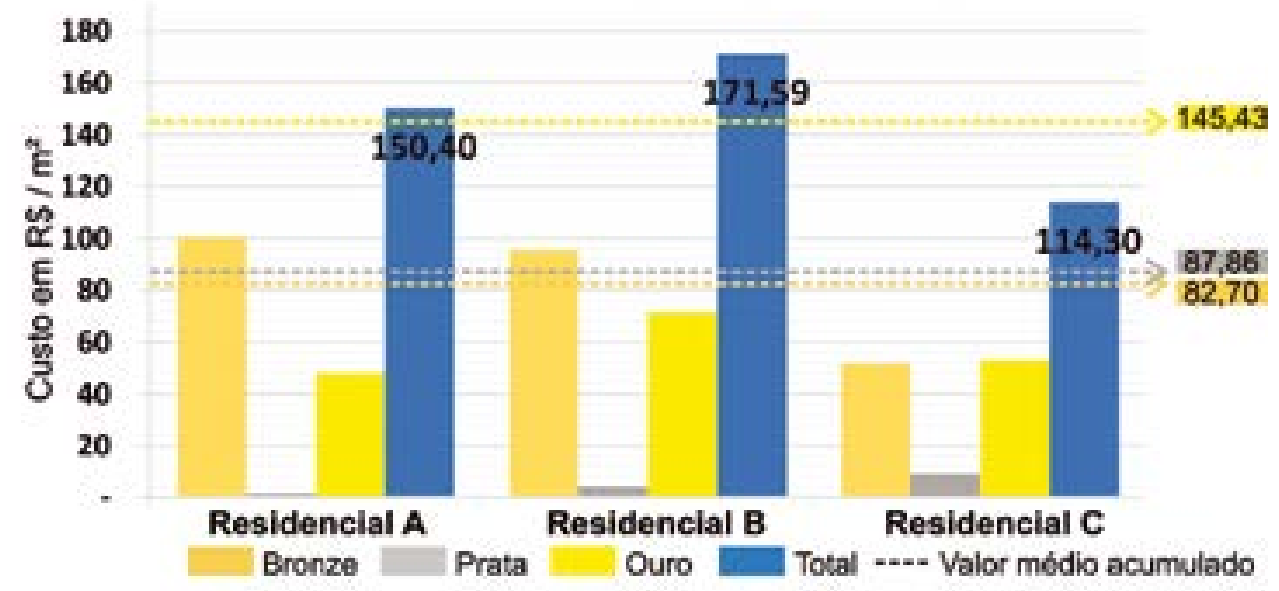

Superintendência Regional da CAIXA. Nesta pesquisa, foram identificados o déficit habitacional municipal e a participação do PMCMV na oferta de moradias.

Para seleção dos estudos de caso, os 27 empreendimentos do PMCMV em Criciúma foram avaliados pelo critério "Qualidade do entorno / infraestrutura" do SCA. Com esta avaliação e posterior contato com as construtoras e escritórios de arquitetura responsáveis pelos projetos, foram definidos os 3 estudos de caso. Os estudos de caso foram então avaliados pelo SCA, verificando seus atendimentos prévios a certificação.

A análise dos projetos pelo SCA ocorreu por meio de 53 critérios, os quais estão divididos em seis categorias: Qualidade Urbana; Projeto e Entorno; Eficiência Energética; Conservação de Recursos Naturais; Gestão da Água e Práticas Sociais. Para a obtenção do nível Bronze, o empreendimento deve atender a 19 critérios obrigatórios. Para atingir os níveis Prata e Ouro, devem ser atendidos os 19 critérios obrigatórios e mais 6 e 12 critérios de livre escolha, respectivamente (CAIXA, 2010).

$\mathrm{Na}$ etapa de proposição, foi realizada inicialmente um projeto piloto, que consistiu em identificar e propor as adequações necessárias, permitindo que o empreendimento estivesse apto para receber cada um dos três níveis de certificação do SCA. Como resultado, foram avaliados os impactos econômicos destas adequações, além do nível de atendimento do empreendimento com a certificação nível Ouro do SCA, frente uma avaliação pelo Procel Edifica.
Após o projeto piloto, o método, revisado, foi replicado nos demais estudos de caso, permitindo posterior análise dos resultados.

\section{RESULTADOS}

Observou-se que, embora não certificados, os estudos de caso atendiam, em média, a 14 critérios do SCA. Por não atenderem a todos os critérios obrigatórios, não estavam aptos à certificação. Porém, por atenderem a critérios de livre escoIha, indicavam uma tendência para a certificação nível Prata.

Por não estarem aptos a certificação, foram propostas adequações para que os edifícios atendessem ao SCA. Com as proposições, constatou-se o potencial de adequabilidade dos edifícios, sendo que, por meio de mudanças simples, foi possível o atendimento de vários critérios. Outros critérios, no entanto, evidenciaram a importância de um estudo de viabilidade, verificando se o local era adequado aos edifícios.

Quanto a eficiência energética, ambos os estudos de caso com certificação nível Ouro pelo SCA, apresentaram uma melhora significativa, passando de uma etiquetagem Procel C para Procel A. Quanto aos impactos econômicos das adequações propostas, identificou-se um incremento médio no custo da obra de $13,05 \%$ e de $\mathrm{R} \$ 145,43 / \mathrm{m}^{2}$ edificado, conforme Figura 1.

Como resultados, apresenta-se o desenvolvimento de um produto de moda e como estratégia de comunicação do lançamento do produto o desenvolvimento de uma embalagem reutilizável. 


\section{CONSIDERAÇÕES FINAIS}

O uso do SCA como método de avaliação da sustentabilidade mostrou-se pertinente a realidade brasileira, abordando, além de indicadores ambientais, indicadores sociais e de avaliação do entorno. No entanto, o atendimento a seus critérios não garante o equilíbrio entre as seis categorias avaliadas. O SCA também não define diferentes pesos para os seus critérios.

Frente a sua notável contribuição para a sustentabilidade na construção civil, associar o SCA a políticas públicas de habitação, seria uma importante ação para viabilizar, intensificar e incentivar a sustentabilidade dos edifícios residenciais brasileiros, popularizando o SCA e seus conceitos de construção sustentável.

\section{REFERÊNCIAS}

1. FUNDAÇÃO JOÃO PINHEIRO - FJP. Centro de Estatística e Informações. Nota técnica: Déficit Habitacional no Brasil - anos 2011 e 2012. Belo Horizonte, 2014. 16 p.

2. CAIXA ECONÔMICA FEDERAL - CAIXA. Minha Casa Minha Vida prevê a entrega de 2 milhões de casas até o fim do ano. Agência Caixa de Notícias, Brasília, p.1-1, 06 jun. 2014.

Projetos reconhecidos. 2015. Disponível em: <http://www. caixa.gov.br/ sustentabilidade / produtos servicos / selo - casa -azul/ Paginas/default.aspx>. Acesso em: 28 jul. 2015.

. Selo Casa Azul: Boas práticas para habitação mais sustentável. São Paulo: Páginas \& Letras, 2010. 204 p.

3. SECRETARIA DO SISTEMA SOCIAL E HABITAÇÃO SSSH. Prefeitura Municipal de Criciúma. Habitação: Programas Habitacionais. Criciúma, 2012. 